Bulg. J. Plant Physiol., Special Issue 2003, 96-109

\title{
AERATION STRESS IN PLANT TISSUE CULTURES
}

\author{
M. B. Jackson
}

School of Biological Sciences, University of Bristol, Woodland Road, Bristol BS8 1UG, U.K.

Summary. The requirement for sterility in plant tissue cultures avoidance of dehydration can impose sealing requirements that severely limit the rate of gas exchange in and out of the culture vessel. Conditions within the culture vessel such as the depth of any water cover, the presence of gelling agents, the bulk and porosity of the tissue and the temperature also strongly influence in vitro rates of gas exchange, primarily driven by diffusion. This article uses elements of Fick's Law of Diffusion to identify key factors limiting gas exchange between culture and its immediate surroundings. In particular, it identifies static liquid media, gelling agents, large tissue mass and warm temperatures as imposing severe limits on diffusive flux for gases such as $\mathrm{O}_{2}, \mathrm{CO}_{2}$ and ethylene. The principle barrier to diffusive exchange of gases between the in vitro and ex vitro atmospheres is the wall of the enclosing vessel. This is invariably made of glass or plastic that is gas-impermeable and well-sealed against evaporative drying or entry of micro-organisms. Cultures enclosed in this way will, inevitably, asphyxiate unless a compensating pathway for diffusive gas exchange is contrived or replaced by some system of convective flow that carries gases to and from the tissue. Supplementing diffusive aeration with convective flow is the basis of most successful hydroponics systems for whole plants and may be a prerequisite for securing levels of aeration suitable for autotrophic cultures. The paramount consideration is the extent to which the total rate of consumption or production of a particular gas by the cultured tissues is matched by the maximum rates of gas transport imposed by the culture itself, its immediate surroundings and the ventilation and sealing system of the culture enclosure.

\section{Introduction}

Techniques of plant tissue culture are a stimulus for basic research and also a tool with potential and proven applications in agriculture, horticulture and forestry. Plant tissue

\footnotetext{
*Corresponding author, e-mail: mike.jackson@bristol.ac.uk and mike.jackson@bbsrc.ac.uk
} 
culture has wide application, encompassing vector and vector-free genetic transformation of cells, embryo rescue, somatic embryogenesis and commercial clonal propagation. Much plant biotechnology requires at least one stage where plant tissue culture is obligatory (Thorpe, 2000). For success, the conditions under which cultures are housed and treated must be strictly adhered to and many papers record how minor changes to the conditions, especially chemical components of the culture medium, enable hitherto recalcitrant cultures to perform in the desired manner.

Ventilation is an issue because the technology of tissue culture is inextricably bound up with a need for sterility and preventing dehydration. Such methods almost always involve some form of sealing of culture vessels. Inevitably, this interferes with the free exchange of gases between the cultured material and the outside atmosphere. The problems can be exacerbated by use of liquid cultures where cells, callus or tissues can be immersed in liquid medium. Much of what is known about the consequences of the resulting poor aeration for healthy plant growth or survival can be inferred from studies of flooding or submergence experienced by plants in the outside world (Vartapetian and Jackson, 1987). Here too, gas exchange is severely compromised by virtue of a dramatic slowing of gas diffusion in and out of the inundated tissue imposed by water. Well-sealed plastic, glass culture vessels and the nutrient medium they contain impose much the same aeration stress since they also impede gas exchange severely. One major difference between the well-sealed tissue culture vessel and plant submergence (the most extreme form of flooding stress) is that in the later case, well-adapted species such as Callitriche platyarpa, rice (Oryza sativa) and Rumex palustris can escape by means of an invigorated underwater elongation that renews contact between shoot and aerial environment (Jackson 1990; Voesenek and Blom, 1999). This is obviously not an option for plant material growing in culture vessels.

Despite the self-evident importance of the gaseous environment for tissue cultures, it is an often neglected component of their technical specification. This shortcoming can have unwelcome consequences for culture performance because of the strong physiological impact of the gases involved, notably $\mathrm{O}_{2}, \mathrm{CO}_{2}$ and $\mathrm{C}_{2} \mathrm{H}_{4}$ (Jackson et al., 1994). This article summarises the processes of tissue culture aeration and highlights some recent developments intended to ensure its adequacy.

\section{Normal plant aeration}

The gases of greatest concern are $\mathrm{O}_{2}, \mathrm{CO}_{2}$ and ethylene. Oxygen and $\mathrm{CO}_{2}$ are principal substrates or products of aerobic respiration and photosynthesis and thus intrinsic to the most basic life-sustaining metabolic pathways of plant cells. By contrast, ethylene is a plant hormone capable of influencing developmental processes such as cell expansion, senescence and differentiation at relatively small concentrations [0.01-10 ppm $(\mathrm{v} / \mathrm{v})]$. The gas is correctly considered as a growth regulator rather than a toxin. The lack of metabolic breakdown and the ease with which it can be measured at small 
concentrations make it a suitable marker of aeration status (Jackson et al., 1987). Other gaseous growth regulators such as methyl jasmonate and nitric oxide may also influence tissue culture development but these have received relatively little research attention in this context.

All living tissues of higher plants, not just the photosynthetic parts, require unimpeded gas exchange to function normally. Figure 1 provides some approximate figures illustrating the scale of gas influx and efflux that underpins normal plant growth and development. Severe impediment to gas movement more than a few hours is usually fatal to growing cells, while partial interference can influence growth rate and the pattern of development. As the term gas exchange implies, both inward and outward efflux of gases are slowed or arrested. This leads not only to a shortage of gases normally provided by the environment but also to an internal accumulation of gases made by the plant and normally excreted at a similar rate by outward diffusion. Thus, when gas exchange is slowed by external conditions plant cultures will experience shortages of oxygen and (in the light) carbon dioxide while accumulating ethylene, a plant hormone that can have a range of responses depending on tissue sensitivities. Other plant-made volatiles such as ethanol and acetaldehyde (Righetti et al., 1990), the free radical nitric oxide and the hormone like molecule methyl jasmonate may also build up, effects of these have not been explored to any great extent but deserve investigation. Nitric oxide could be generated from nitrite produced by nitrate reductase activity. It can be harmful by causing oxidative damage via the production of oxygen superoxide $\left(\mathrm{O}_{2}^{-}\right)$as well as being a possible signalling molecule for certain developmental processes (Sakihama et al., 2002). There is a Clarke type NO electrode and a fluorescence method for NO detection and it can also be measured by laser photoacoustics.

\section{Aeration by diffusion}

The principal mechanism that propels gas exchange in and out of a plant tissue is net diffusion down concentration gradients. The process is summed up by Fick's Law of Diffusion that can be expressed as $\mathrm{Q} / \mathrm{t}=\mathrm{D} * \mathrm{~A}\left(\mathrm{C}_{\mathrm{in}}-\mathrm{C}_{\text {out }}\right) / \mathrm{Th}$, where $\mathrm{Q} / \mathrm{t}=$ amount of gas moved per second (flux density); $\mathrm{D}=$ Diffusion coefficient of the medium through which the gas is moving; $A=$ cross sectional area of diffusion pathway; $\mathrm{C}_{\mathrm{in}}=$ concentration at start of pathway; $\mathrm{C}_{\text {out }}=$ concentration at end of pathway; $\mathrm{Th}=$ length of diffusion pathway. Factors that influence the components of this equation and thus impact on the rate of gas transport (flux density) are now examined.

\section{Flux density}

Flux density $(\mathrm{Q} / \mathrm{t})$ is the first term in the Fick's Law equation $\left(\mathrm{Q} / \mathrm{t}=\mathrm{D} * \mathrm{~A}\left(\mathrm{C}_{\mathrm{in}}-\mathrm{C}_{\text {out }}\right) / \mathrm{Th}\right)$. Its value is affected by the physical environment of the tissue and the morphology of 
the tissue itelf. Whatever the maximum possible flux of a gas to the surface of the tissue or cell turns out to be in a given set of circumstances, it must be judged against what the tissue or cell actually requires to sustain normal rates of metabolism or to keep internally generated gases below some activity threshold. Oxygen flux density in relation to root growth will be used as an example, in a situation where the maximum oxygen flux rate to a root is depressed by the high diffusion resistance imposed by submergence in water. Cereal root respiration rate in the elongating apex can be in the order of $1.56 \mu \mathrm{mol} . \mathrm{kg}^{-1} \cdot \mathrm{s}^{-1}$ or $50 \mathrm{ng} \mathrm{O}_{2} \mathrm{~cm}^{-2}$ of root surface $\mathrm{min}^{-1}$ at $10^{\circ} \mathrm{C}$. The expression using surface area is especially useful because it highlights the importance of area available for gas capture or release. Using platinum electrodes, Blackwell and Wells (1983) showed that when the equilibrium concentration of dissolved oxygen in the flooded soil fell from $21 \%$ to $15 \%$, in response to consumption by microorganisms, the maximum possible inward flux density of $\mathrm{O}_{2}$ toward the root decreased from $>80 \mathrm{ng} \mathrm{O}_{2} \mathrm{~cm}^{-2}$ of root surface $\mathrm{min}^{-1}$ (the value for freshly flooded soil) to below $30 \mathrm{ng} \mathrm{O}_{2} \mathrm{~cm}^{-2} \cdot \mathrm{min}^{-1}$, a value close to the respiratory demand of the root. At this point, root elongation became retarded. They also showed that, for elongation to be stopped completely, the flux density must fall almost to zero. From this study we learn that (i) some loss of gas diffusion capability for $\mathrm{O}_{2}$ can be sustained without damage (from $>80 \mathrm{ng} \mathrm{O}_{2} \mathrm{~cm}^{-2} \cdot \mathrm{min}^{-1}$ down to $<30 \mathrm{ng} \mathrm{O}_{2} \mathrm{~cm}^{-2} \cdot \mathrm{min}^{-1}$, in this case), (ii) to depress growth, flux densities must fall to below those potentially generated by rate of respiration and (iii) an almost total arrest of $\mathrm{O}_{2}$ influx is needed to stop growth and possibly kill the root.

The seeming tolerance of quite substantial decreases in $\mathrm{O}_{2}$ flux density is partly attributable to the large amount of $\mathrm{O}_{2}$ present in the air $(21 \% \mathrm{v} / \mathrm{v})$. This ensures a maximum flux density in water that can often exceed the needs of respiring tissue (see below for qualifications). This can be true, in well-stirred water, despite the limited solubility of $\mathrm{O}_{2}$ in water that reduces the concentration from $8.31 \mathrm{~mol} . \mathrm{m}^{-2}$ in air to 0.25 mol. $\mathrm{m}^{-3}$ in water $\left(\right.$ at $25^{\circ} \mathrm{C}$ ). An exception may be roots in tissue culture growing at optimal temperatures and supplied in vitro with external sugar (Asplund and Curtis, 2001). Here, local root-tip respiration is so intense that fluxes through well-stirred water in equilibrium with air are too slow to sustain maximum repiration rates. A second explanation for the insensitivity of tissue to modest depressions in $\mathrm{O}_{2}$ availability is that the affinity for oxygen shown by cytochrome oxidase, the terminal oxidase in mitochondrial electron transport, is extraordinarily strong $\left(\mathrm{K}_{\mathrm{m}}\right.$ approx. $\left.0.14 \mathrm{mmol} . \mathrm{m}^{-3}\right)$. It is instructive to compare these figures with those for $\mathrm{CO}_{2}$, the photosynthetic progenitor of environmental $\mathrm{O}_{2}$. $\mathrm{CO}_{2}$ flux densities required to support photosynthesis are similar or higher than those required to support respiration with external $\mathrm{O}_{2}$ (Fig. 1). Although $\mathrm{CO}_{2}$ is also much more soluble in water than $\mathrm{O}_{2}$; at $25^{\circ} \mathrm{C}$ (the ratio of dissolved $\mathrm{CO}_{2}$ /gas-phase being approximately 0.76 at neutral $\mathrm{pH}$, while the ratio for oxygen is only 0.03), the small amount of $\mathrm{CO}_{2}$ in air (approx. $360 \mathrm{ppm}, \mathrm{v} / \mathrm{v}$ ) is insufficent to generate dissolved concentrations that match those of dissolved $\mathrm{O}_{2}$. At 


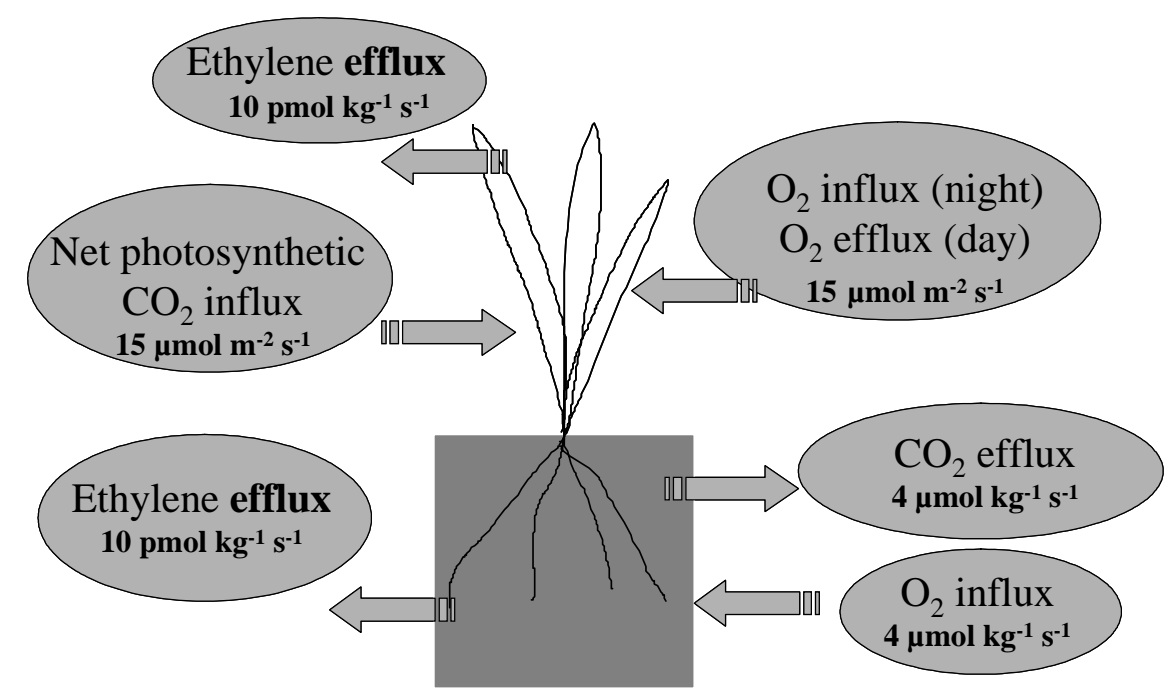

Fig. 1. Schematic illustration of the pattern and approximate scale of gas efflux and influx that underlies normal plant growth and development. Sources for gas flux data include: Haupt-Herting and Fock (2002); Jackson (1980), Armstrong et al (1991)

$25^{\circ} \mathrm{C}, \mathrm{CO}_{2}$ concentrations may attain only $11.4 \mathrm{mmol} \cdot \mathrm{m}^{-3}$ compared with the concentration of $\mathrm{O}_{2}$ in aerated water of $0.266 \mathrm{mmol} . \mathrm{m}^{-3}$, a difference of almost 2000 . Since the inward flux densities of $\mathrm{CO}_{2}$ needed for photosynthesis are similar or greater than those of $\mathrm{O}_{2}$ needed for respiration it is clear that autotrophic plants are much more at risk from $\mathrm{CO}_{2}$ starvation than from $\mathrm{O}_{2}$ starvation. A further contributing factor to this greater sensitivity to decreased availability of $\mathrm{CO}_{2}$ is the low affinity for $\mathrm{CO}_{2}$ of Rubisco, the enzyme largely responsible for capturing photosynthetic $\mathrm{CO}_{2}\left(\mathrm{~K}_{\mathrm{m}}\right.$ for $\mathrm{CO}_{2}-10$ mmol.m $\mathrm{m}^{-3}$ compared to $0.14 \mathrm{mmol} . \mathrm{m}^{-3}$ for $\mathrm{O}_{2}$ ). This high $\mathrm{K}_{\mathrm{m}}$ for $\mathrm{CO}_{2}$ by Rubisco is almost the same as that for the concentration of $\mathrm{CO}_{2}$ dissolved water in equilibrium with air, indicating the impossiblility of submerged leaves from photosynthesising normally. Data for $\mathrm{O}_{2}$ and $\mathrm{CO}_{2}$ used in these comparisons can be found in Armstrong (1979).

This analysis makes it apparent that while plants can sustain considerable interference in ventilation before mainstream respiration is strongly inhibited, almost no interference in aeration is possible in autotrophic plants before photosynthesis is depressed. This means that diffusion-driven $\mathrm{CO}_{2}$ supply is rarely adequate for photosynthesis in tissue cultures, imposing the necessity of the sugar supplements almost universally used in tissue cultures. Even for oxygen, the leeway in diffusion losses can be sustained before damage sets-in, is strongly eroded by other factors such as warmer temperatures and decreasing surface to volume ratios. Thus, although the physical processes of diffusion is largely unresponsive to temperature per se, the flux required by the tissue increases dramatically with warming, typically doubling every $10^{\circ} \mathrm{C}$ 


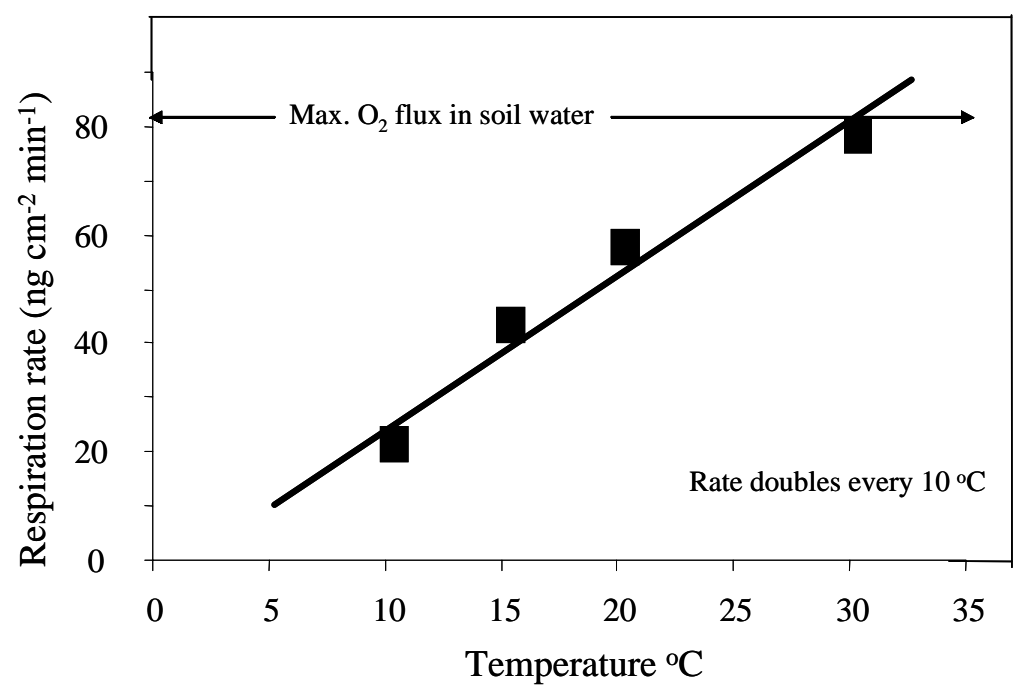

Fig. 2. Relationship between temperature and the rate of respiration expressed in terms of an inward flux density of $\mathrm{O}_{2}$ required to service respiratory demand of plant tissue such as a cereal root axis. While at cool temperatures (e.g., $15^{\circ} \mathrm{C}$ ) the requirement is smaller than the maximum flux density possible in water equilibrated with air (approx. $80 \mathrm{ng} . \mathrm{cm}^{-2} \cdot \mathrm{min}^{-1}$ ), it is barely inadequate to service the complete needs of roots at $30^{\circ} \mathrm{C}$.

(Fig. 2). At about $30^{\circ} \mathrm{C}$, demand by a cereal root matches the maximum flux that it possible from water in equilibrium with air. Clearly, increasing temperature markedly increases the required flux, placing a much larger demand on the gas exchange capacity of the surroundings. The flux required is also raised very considerably by radial growth of the tissue. This comes about because, as tissue bulk increases, the surface area available to service the gas exchange needs of each unit of tissue volume decreases. In a tissue culture, the leeway for how much aeration can be impaired before a tissue culture will suffer from $\mathrm{O}_{2}$ shortage is abolished as size of tissue mass increases (Fig. 3). The effect can only be ameliorated if the tissue mass is highly porous and permeated by gas-filled intercellular spaces, which is uncommon. It may be concluded that any margin that exists before restricted aeration damages tissue cultures through $\mathrm{O}_{2}$ shortage can be lost to warmer temperatures and to increasing tissue volume.

\section{Diffusion coefficient of the diffusion medium}

The diffusion coefficient (D) of the medium or barrier surrounding the tissue is the second component of the Fick's Law equation $\left(\mathrm{Q} / \mathrm{t}=\mathrm{D} * \mathrm{~A}\left(\mathrm{C}_{\mathrm{in}}-\mathrm{C}_{\text {out }}\right) / \mathrm{Th}\right)$. This value quantifies the relative ease with which the gas diffuses through a given medium (e.g., air, water, tissue) along its path to the tissue or cell. The very small coefficient of gas diffusion in water compared to that in air makes water a principle enemy of tissue 


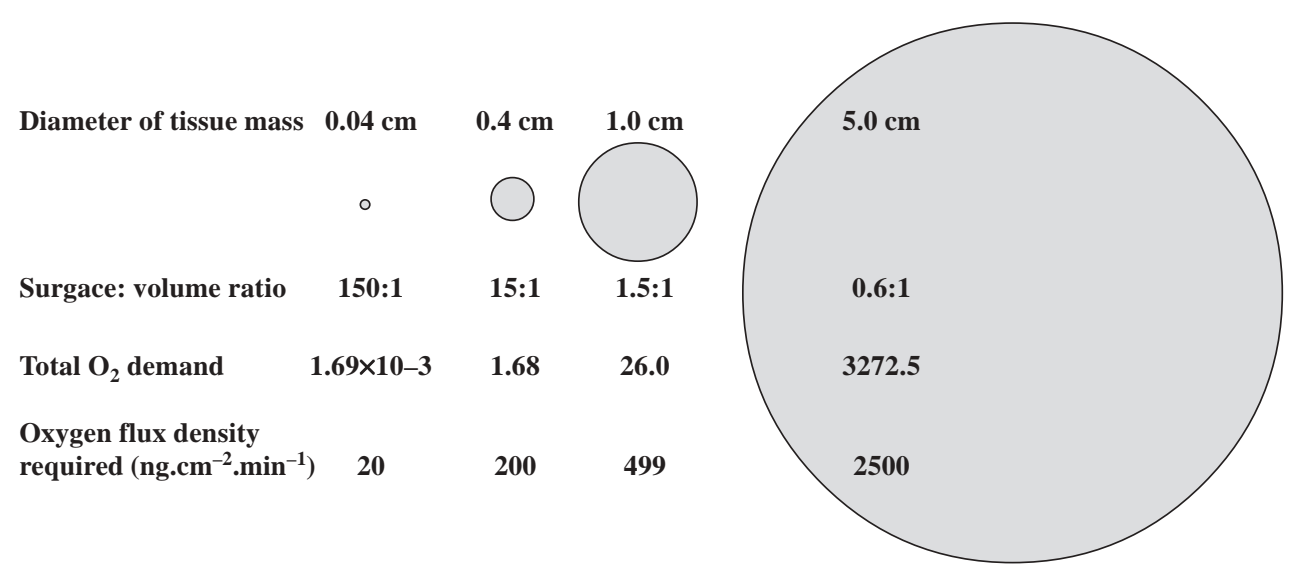

Fig. 3. Illustration of the impact of increasing tissue bulk on surface area: volume ratio, total respiration and required oxygen flux densities per unit surface area (based on spheres).

aeration. For $\mathrm{O}_{2}$, ethylene and $\mathrm{CO}_{2}$, the diffusion coefficient in water is almost 10,000 times smaller than in air (in air: $0.201 \mathrm{~cm}^{2} . \mathrm{s}^{-1}$; in water: $2.1 \times 10^{-5} \mathrm{~cm}^{2} \cdot \mathrm{s}^{-1}$ ). Adding a solid matrix such as agar or similar setting agent increases the barrier to gas diffusion even more. It also imposes a large unstirred layer that, in effect, strongly decreases the concentration of externally derived gases at the tissue surface thus slowing the rate of gaseous diffusion into the cells. This effect also enhances the trapping effect of water on metabolically generated gases such as ethylene. The work of Barrett-Lennard and Dracup (1988) and Verslues, Ober and Sharp (1998) illustrates the highly damaging impact of gelling agents on aeration and growth.

In most tissue culture systems, the strongest diffusion barrier is the container itself, which is usually fabricated from material that is totally impermeable to gases. For cultures to do well in such containers they must either be very large in relation to the size of the culture or be made to leak gas in some way. Obvious ways to achieve leakage include loosening the closure or inserting a gas-permeable membrane (e.g., polypropylene). Cultures of Ficus elastica in $305 \mathrm{ml}$ plastic Magenta boxes were found to benefit from leakage rates that gave a half time of gas replacement of about $8 \mathrm{~h}$. The benefit was attributed to a decrease in accumulated ethylene, resulting in enhanced leaf expansion (Jackson et al., 1991).

\section{Cross sectional area of the diffusion pathway}

The cross sectional area of the diffusion pathway (A) of the medium or barrier is the third component of the Fick's Law equation $\left(\mathrm{Q} / \mathrm{t}=\mathrm{D} * \mathbf{A}\left(\mathrm{C}_{\mathrm{in}}-\mathrm{C}_{\mathrm{out}}\right) / \mathrm{Th}\right)$. Obviously, the larger the area across which gases can diffuse the more gas can be moved in total in a given time. One important aspect of this effect is the influence of the size and format of the tissue mass; a larger mass creating a smaller area for diffusion per unit 
volume of tissue. The impact of cross sectionl area also means that the amount of internal surface area of tissue that is in contact with a gas phase (e.g., that created by aerenchyma) will also affect the gaseous flux in proportion to the diffusive surface area this creates. These effects have already been considered above.

\section{Length of the diffusion pathway}

The length of the diffusion pathway (Th) is the final term in the Fick's Law equation $\left(\mathrm{Q} / \mathrm{t}=\mathrm{D} * \mathrm{~A}\left(\mathrm{C}_{\text {in }}-\mathrm{C}_{\text {out }}\right) / \mathrm{Th}\right)$. The longer the path the greater the total resistance to gaseous diffusion. Tissue itself impedes its own aeration. After all, cells are mostly water. If tissues enlarge radially, the total path length to the centre of the mass also grows. For this reason, a large tissue mass may result in a poorly aerated interiors leading possible to anaerobic or hypoxic cores while more peripheral cells remain better aerated. There is an added problem connected with the thickness of the tissue barrier. For oxygen, it is that more and more of it is consumed as the pathway lengthens. This adds to the probability of deficiency deeper into the tissue since the concentration gradient driving further inward flow drops away as more and more is used in respiration. These affects are additional to the small surface to volume ratios that typify larger masses of tissue and raise detrimentally the requirements for gas exchange at the tissue external surface (as discussed above). Diffusion, within tissue can also be impeded more strongly by certain kinds of differentiation (e.g., lignified parts). These can impose sharply internally delineated radial-diffusion barriers (Armstrong et al., 2000).

Outside the tissue, the thickness (depth) of any water covering also impacts on gas diffusion. The effect is illustrated in calculations for ethylene accumulating at the surface of a root producing ethylene at a known rate (Jackson, 1979). When the radius of a water covering over the root of radius $0.025 \mathrm{~cm}$ is increased from $0.25 \mathrm{~cm}$ to $2.0 \mathrm{~cm}$, ethylene build up at the root surface is enhanced 10-fold. A similar effect in reverse is seen for $\mathrm{O}_{2}$. Thus, there is a benefit to aeration from maintaining water cover that is as shallow as possible or is intermittent to allow periods of relief from gas entrapment or exclusion.

\section{Driving force for diffusion}

The driving force for directional net diffusion is the fourth bracketed term in the Fick's Law equation $\left(\mathrm{Q} / \mathrm{t}=\mathrm{D} * \mathrm{~A}\left(\mathbf{C}_{\mathrm{in}}-\mathbf{C}_{\text {out }}\right) / \mathrm{Th}\right)$. It comprises the difference in concentration between source and sink. For $\mathrm{O}_{2}$ and $\mathrm{CO}_{2}$ it is appropriate to consider $\mathrm{C}_{\text {out }}$ as the atmospheric concentrations and $\mathrm{C}_{\text {in }}$ usually lying somewhere between atmospheric and zero. For ethylene we take $\mathrm{C}_{\text {out }}$ to be zero and $\mathrm{C}_{\text {in }}$ to be up to tens of parts per million and thus possibly above physiologically active levels. Clearly, $\mathrm{C}_{\mathrm{i}}$ is the physiologically active component and is affected by all the factors considered above that 
influence gaseous flux densisty. Thus, managing tissue culture aeration is about managing $\mathrm{C}_{\mathrm{i}}$ to avoid physiologically damaging concentrations developing.

\section{Approaches towards improving tissue culture aeration}

The key to adequately aerating the cultured tissue itself is to maximise the concentration gradient for the gas between the interior and the immediate exterior of the tissue and to minimise the flux density per unit surface area neeed to sustain normal growth, respiration and where appropriate, photosynthesis. Our analysis of components of the Fick's Law equation has indicated this can be achieved by increasing diffusive ventilation of culture volume, minimising resistances to the movement of gas down that gradient, keeping cultures cool, minimising thickness of any water cover and avoiding solid media such as agar. A further important consideration is minimizing tissue volumes. This both decreases the flux density per unit surface area of tissue required to aerated the tissue and shortens internal diffusion pathways. Actual success is determined by achieving the flux density of gas needed to support the desired growth rate or pattern of development. This is especially demanding if the cultures are to be autotrophic since $\mathrm{CO}_{2}$ is almost always in short supply The aim is to optimise $\mathrm{C}_{\mathrm{i}}$ for key gases such as $\mathrm{CO}_{2}, \mathrm{O}_{2}$ and ethylene. This aim can be helped simply by having the vessels large in relation to the amount of tissue since this provides greater reserves of $\mathrm{O}_{2}$ or $\mathrm{CO}_{2}$ and a more effective dilution of metabolically generated gases such as ethylene.

However, in practice satisfying the aeration needs of tissue cultures by facilitating diffusive aeration and maximising vessel volumes alone is almost impossible, especially if autotrophic cultures are needed. Thus, additional measures are required. One approach is to side-step some of the problems. The most widespread such approach is to overcome the need for adequate flux of external $\mathrm{CO}_{2}$ by supplying respirable sugars such as sucrose. This is widely practiced and does not warrant further discussion here accept to point out the heightened need for total sterility the use of sugar demands and the problems of adaptation this practice poses for any later move to autotrophic life outside the culture vessel. A lack of photosynthetic $\mathrm{CO}_{2}$ fixation also deprives the cultures of the $\mathrm{O}_{2}$ this generates. A second example of side-stepping to minimise $\mathrm{C}_{\text {in }}$ of ethylene by reducing $\mathrm{C}_{\text {out }}$ with an absorbant such as alkaline potassium permanganate or mercuric perchlorate. Enhanced leaf expansion rates in $F$. lyrata have reported using this approach (Jackson et al., 1987; 1991). An closely related measure is to incorporate an inhibitor of ethylene action such as silver nitrate (e.g., Armstrong et al., 1997) or 1-methylcyclopropene, a recently developed and very effective gaseous inhibitor of ethylene action (Sisler et al., 1996)

More satisfactory than side-stepping is to introduce an element of convection flow (mass flow) of the air (or water where liquid cultures are uses) to augment the contribution from diffusion alone. With this mechanism of aeration, it is useful to consider 
the surrounding water or air as a physical carrier of gases to and from the tissue rather than a diffusion medium or barrier. For convention to be effective, the air or water must move across the cultured material. Various methods have been adopted in attempts to achieve this simply and effectively.

\section{Harnessing convective flow}

An elegant non-mechanized solution to the problem of how to ventilate tissue culture vessels with convection is provided by Armstrong and colleagues (Armstrong et al., 1997; Zobayed et al., 2001). It is based on a mechanism operating in whole plants of wetland species such as Phragmites australis. Here, mass flow of gases is driven initially by diffusion of $\mathrm{N}_{2}$ and $\mathrm{O}_{2}$ through stomata into the humid interior of the leaf down a concentration gradient. This gradient arises as a result of extra dilution of $\mathrm{N}_{2}$ and $\mathrm{O}_{2}$ in the plant's interior by abundant water vapour. The pore size of stomata is such that the resistance they offer to inward diffusion is less than outward mass flow of gas. Thus, inward diffusion of $\mathrm{N}_{2}$ and $\mathrm{O}_{2}$ (and other more minor components of air) results in an internal pressurization of the plant's gas spaces. This force is then capable of driving mass flow along interconnected gas-filled spaces. This mechanism of humidity-induced convective throughflow can be harnessed to ventilate tissue culture vessels with a sterile flow of air. Pressurization is achieved by connecting the culture vessel to a port with an overlying microporous membrane with a small pore size $(0.03 \mu \mathrm{m})$ overlying but no quite touching water held in a small reservoir. This creates a humidity-driven inflow and pressurizes the culture vessel. A second port protected by a membrane of larger pore size $(0.2 \mu \mathrm{m})$ creates an exhaust of low resistance to mass flow (Fig. 4). The outcome is a convective throughflow of air that is fast enough to clear half any accumulated ethylene within $30 \mathrm{~min}$ and to sustain greater rates of dry matter accumulation through enhanced $\mathrm{CO}_{2}$ supply (Zobayed et al., 2001).

For tissue cultures where liquid medium is used and especially where mass production of somatic embryos in bioreactors is required, highly mechanised systems of introducing convective aeration have been devised. Here, three new elements are intro duced to supplement diffusive aeration with mass flows. Firstly, air is pumped over the cultures to carry $\mathrm{O}_{2}$ and $\mathrm{CO}_{2}$ to the plants and substrate and aid removal of metabolically produced gases from the tissues. Secondly, the air flow is fertilized with $\mathrm{CO}_{2}$ to encourage further photosynthetic assimilation if convention flow of air does not provide a $\mathrm{CO}_{2}$ flux density for the desired rate of photosynthesis Thirdly, the roots are greown in a porous medium to promote their aeration by diffusion. This is also periodically flushed with aerated nutrient solution to bring these resources to the roots by mass flow. A set-up such as this is described by Afreen et al. (2002). The plants produced by such a system were notable for their rapid adaptation to ex vitro conditions

A quite different approach to overcoming aeration problems is taken by BarryEtienne et al. (2002). These authors recognise that the in vitro nature of culture systems 


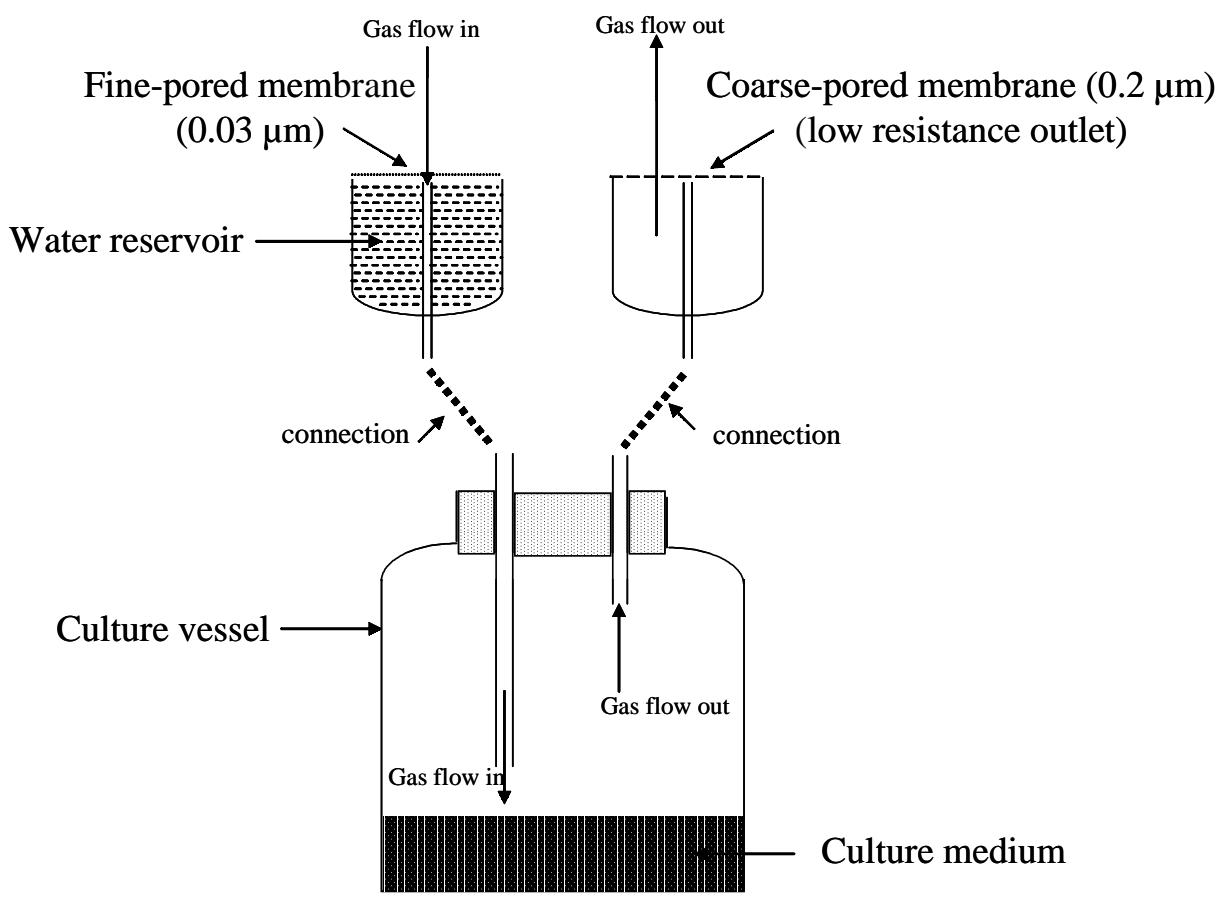

Fig. 4. Diagrammatic illustration of how humidity-driven inward diffusion of air across an membrane of fine pores can create a pressure driven flow of sterile air through the culture vessel and out through a second port protected by a membrane of larger pore size. Taken from Armstrong et al 1997.

is the principle problem for aeration. Thus, they propose keeping any in vitro phase in micropropagation as short as possible and returning the tissues to open septic environment at the earliest opportunity. This philosophy was anticipated several years earlier by Firn et al. (1994). In the system of Barry-Etienne, autotrophic somatic embryos, generated in a sophisticated illuminated bioreactor are transferred at an early stage (the cotyledon stage) to high density cells of sterilised soil-containing compost in a glasshouse under shade and carefully watered. The $60 \%$ that survived grew on quite quickly to form well-rooted normal plants with no need for troublesome rehabilitation.

\section{Conclusion}

Gas exchange in tissue culture can involve two different although not entirely unconnected processes. These are simple diffusion down concentration gradients and/or convective (mass) flow. In the latter, gases are delivered to plant tissue by a flow of solvent (water) or carrier gas (air) that is propelled over the surface of cells or tissue by an external force, usually a pressure gradient. However, within the tissue mass itself, gas 
movement is effected almost exclusively by diffusion. Only in whole plants growing in the natural environment where extensive interconnected porous tissue (aerenchyma) is present, can internal convective flow play a significant role in aeration (e.g., in Phragmites - Armstrong, et al., 1992). However, convective flow within culture vessels can readily be harnessed to increase rates of tissue culture gas exchange by contriving slow pressure-driven gas flows (e.g., Zobayed et al., 2001) or by flowing or stirring aerated medium over the cultured tissue. Opportunities for enhancing the diffusive aeration of tissue cultures are many and include temporary immersion set-ups, fitting gas permeable ports to culture vessels, adopting loose-fitting lids. The demands on the ventilation system can be minimised by restricting the depth of culture medium to thin films, keeping tissue bulk to a minimum and adopting cool temperatures. The biological effectiveness of any particular system will be affected by many factors. Paramount is the total rate of consumption or production of a particular gas by the culture in relation to the influx and efflux rates achievable by the enclosing environment and the ventilation system adopted.

\section{References}

Afreen F, Zobayed SMA, Kozai T (2002). Photoautotrophic culture of Coffea arabusta somatic embryos: development of a bioreactor for large scale plantlet conversion from cotyledonary embryos. Annals of Botany, 90, 21-29.

Armstrong W (1979). Aeration in higher plants. Advances in Botanical Research 7, 225-332

Armstrong J, Armstrong W and Beckett PM (1992). Phragmites australis: Venturi-induced and -humidity-induced pressure flows enhance rhizome aeration and rhizosphere oxidation. The New Phytologist, 120, 197-207

Armstrong W, Beckett PM, Justin SHFW, Lythe S (1991). Modelling, and other aspects of root aeration by diffusion. In: Plant life under oxygen deprivation: ecology, physiology and biochemistry, Jackson MB, Davies DD, Lambers H, eds. The Hague, SPB Academic, 267-282.

Armstrong J, Lemon EEP, Zobayed SMA, Justin SHFW, Armstrong W (1997). A humidityinduced conventive throughflow and ventilation system benefits Annona sqamosa L. explants and coconut calloid. Annals of Botany, 79, 31-40.

Armstrong W, Cousins D, Armstrong J, Turner DW, Beckett PM (2000). Oxygen distribution in wetland plant roots and permeability barriers to gas exchange with the rhizosphere: a microelectrode and modelling study with Phragmites australis. Annals of Botany, 86, 687-703.

Asplund PT, Curtis WR (2001). Intrinsic oxygen use kinetics of transformed plant root culture. Biotechnology Progress, 17, 481-489.

Barry-Etienne D, Bertrand B, Vasquez N, Etienne H (2002). Comparison of somatic embryogenesis-derived coffee (Coffea arabica $\mathrm{L}$.) plantlets regenerated in vitro and ex vitro: morphological, mineral and water characteristics. Annals of Botany, 90, 77-85. 
Blackwell PS, Wells EA (1983). Limiting oxygen flux densities for oat root extension. Plant Soil, 73, 129-139

Barrett-Lennard EG and Dracup MA (1988). A porous agar medium for improving the growth of plants under sterile conditions. Plant and Soil, 108, 294-298

Firn RD, Sharma N, Digby J (1994). Physiology, growth and development of plants and cells in culture - the way ahead. In: Physiology, growth and developments of plants in culture, Lumsden PJ, Nicholas JR and Davies WJ, eds. Dordrecht: Kluwer Academic, 409-2421.

Haupt-Herting S, Fock HP (2002). Oxygen exchange in relation to cardon assimilation in water-stressed leaves during photosynthesis. Annals of Botany, 89, 851-859.

Jackson, M.B. (1980). Aeration in the nutrient film technique of glasshouse crop production and the importance of oxygen, ethylene and carbon dioxide. Acta Horticulturae, 98, 61-78.

Jackson, M.B. (1990). Hormones and developmental change in plants subjected to submergence or soil waterlogging. Aquatic Botany, 39, 49-72.

Jackson MB, Blackwell PS, Chrimes JR and Sims TV, (1984). Poor aeration in NFT and a means for its improvement. Journal of Horticultural Science, 59, 439-448

Jackson, M.B. , Abbott, A.J., Belcher, A.R. and Hall, K.C. (1987). Gas exchange in plant tissue cultures. In: Advances in the chemical manipulation of plant tissue cultures Monograph No. 16, Jackson MB, Mantell SH, Blake J eds. Bristol: British Plant Growth Regulator Group, 57-72.

Jackson, M.B., Abbott, A.J., Belcher, A.R., Hall, K.C., Butler, R. and Cameron, J. (1991). Ventilation in plant tissue cultures and effects of poor aeration on ethylene and carbon dioxide accumulation, oxygen depletion and explant development. Annals of Botany, 67, 229-237.

Jackson MB, Belcher AR and Brain P, (1994). Measuring shortcomings in tissue culture aeration and their consequences for explant development. In: Physiology, growth and developments of plants in culture, Lumsden PJ, Nicholas JR and Davies WJ, eds. Dordrecht: Kluwer Academic, 191-203.

Righetti B, Magnanini E, Infante R, Predieri S (1990). Ethylene, ethanol, acetaldehyde and carbon dioxide released by Prunus avium shoot cultures. Physiologia Plantarum, 78, 507-510.

Sakihama Y, Nakamura S, Yamasaki H (2002). Nitric oxide production mediated by nitrate reductase in the green alga Chlamydomonas reinhardtii: an alternative NO pathway in photosynthetic organisms. Plant and Cell Physiology, 43, 290-297.

Sisler EC, Serek M, Dupille E (1996). Comparison of cyclopropene, 1-methylcyclopropene and 3,3-dimethylcyclopropene as ethylene antagonists in plants. Plant Growth Regulation, 18, 169-174.

Thorpe TA (2000). History of plant cell culture In: Plant cell tissue culture. Techniques and experiments, Smith RH, ed. London: Academic Press, 1-32

Vartapetian, B.B. and Jackson, M.B. (1997). Plant adaptation to anaerobic stress. Annals of Botany 79 (Supplement A), 3-20. 
Thorpe, TA. (2000). History of plant cell culture In: Plant cell tissue culture. Techniques and experiments, Smith RH, ed. London: Academic Press, 1-32.

Verslues PE, Ober ES and Sharp RE (1998). Root growth and oxygen relations at low water potentials. Impact of oxygen availability in polyethylene glycol solutions. Plant Physiology, 116, 403-1412

Voesenek, LACJ, Blom CWPM (1999). Stimulated shoot elongation: a mechanism of semiaquatic plants to avoid submergence stress. In: Plant responses to environmental stresses: from phytohormones to genome reorganization, Lerner HR, ed. New York: Marcel Dekker, 431-448.

Zobayed SMA, Armstrong J and Armstrong W (2001). Micropropagation of potato: evaluation of closed, diffusive and forced ventilation on growth and tuberization. Annals of Botany, 87, 53-59 